\title{
Energy, economic and environmental assessment of the utilization of heat pumps for buildings heating in the Italian residential sector
}

\author{
Vincenzo Bianco*, Giorgio Piazza, Federico Scarpa, Luca A. Tagliafico \\ Dipartimento di Ingegneria Meccanica, Energetica, Gestionale e dei Trasporti, Università degli \\ Studi di Genova, Via All’Opera Pia 15/A, 16145 Genoa, Italy
}

Email: vincenzo.bianco@unige.it

\begin{abstract}
Buildings heating is one of the main source of primary energy consumption, therefore there is a high pressure for finding solution able to reduce the consumption with consequent positive impacts on the environment. In the last years, it has been detected all around Europe an aggressive development of renewable energy sources in the electricity sector. Thus, an increasing share of electricity is now generated from renewables, which can be seen as a clean and sustainable source of energy. On the contrary, most of the heating systems available in buildings are based on fossil fuels boilers, usually fueled with fuel oil or natural gas. These fuel sources are characterized by pollutant emissions, namely $\mathrm{CO}_{2}, \mathrm{NO}_{x}, \mathrm{SO}_{x}$, soot, especially in the case of fuel oil. By developing an energy system model, the present paper shows that the switching from fossil fuel to electricity of buildings heating systems can support the reduction of primary energy consumption thus guaranteeing better economic and environmental performances. If an increasing amount of electricity is generated by using renewables energies, therefore the carbon intensity of electricity generation substantially decreases. The paper demonstrates that if the $20 \%$ of heating demand is covered by heat pumps a saving of $4 \%\left(27 \mathrm{TWh}_{\mathrm{t}}\right)$ in primary energy and $4 \%(\% \mathrm{Mt})$ of carbon emissions can be achieved.
\end{abstract}

Keywords: Energy Planning, Heat Pumps, Energy Strategy, Energy Management, Energy Policy.

\section{INTRODUCTION}

Buildings are responsible for a large share of primary energy consumption. As given in [1], final energy consumption in 2013 originated from the household sector amounted to $3441 \mathrm{TWh}$, equal to $26.8 \%$ of the $\mathrm{EU}$ consumption, and second only to transport (31.6\%).

According to these data, household building sector offers relevant possibilities to decrease its energy consumption. In particular, most of the consumption is due to winter heating, which is usually provided by natural gas or fuel oil boilers.

This also causes a relevant environmental impact in the cities, where, during the heating season, the concentration of pollutants in the atmosphere arises, especially when there is a massive utilization of fuel oil boilers.

Moreover, both fuel oil and natural gas are subjected to significant market fluctuations, which can cause major economic impacts [2]. These fluctuations are highly uncertain and they can depend on a number of reasons, which are out of the control of consumers and, often, also from their governments [2]. Therefore, it is also highlighted a problem in terms of energy supply security [3]. In fact, the 2014 tensions between the Russian Federation and Ukraine reignited European concerns about the security of its natural gas supply [3]. These concerns were confirmed during the 2016 crisis between these two countries.

In such a scenario, domestic customers are the weakest players, because they are "captive". This means that their energy demand (e.g. heat demand in the present case) is not elastic to the price, which means that domestic consumers do not react to price signal, because their opportunities for a fuel switching are quite limited.

An opportunity to increase the elasticity of the heat demand of European domestic customer could be represented by the increase of RES share in the electricity generation mix.

As highlighted by many authors [4-6], RES electricity generation, particularly solar PV and wind, had an impressive growth in EU countries during the last ten years. This huge increase is the result of the implementation of energy policies which strongly supported RES development both from the financial and regulatory point of view [7].

On the other hand, the relevant increase of RES share in the electricity generation sector had the effect to reduce notably its carbon intensity, therefore it could be reasonable to evaluate a possible switching of heat generation from the natural gas market to the electricity market by utilizing electrical heat pumps for buildings heating.

As noticed in [8], in different EU countries, for example Italy, simple "air to air" heat pumps are already installed in many households for summer cooling purposes, therefore their 
usage for winter heating should be simply stimulated. On the contrary, if there is the necessity to install a heat pumps, it is likely that customers have the "willingness" to do it, because the appliance is perceived has a white good, rather than a deep renovation of the dwelling, which implies a hard work.

The idea of the present work is to analyze if the possible fuel switching of heat demand from the natural gas market to the electricity market is more energy efficient, determines a lower environmental impact and is more convenient from the economic point view.

In particular, the main aim is to understand if there is an optimal amount of the heat demand to be satisfied by heat pumps in order to minimize the environmental impact.

To perform the assessment an energy model is conceived by using the software EnergyPLAN [10], whose validity for the analysis of such kind of problems has been assessed in previously published papers [10].

\section{SNAPSHOT OF THE ENERGY CONTEXT}

During the last ten years the Italian electricity generation sector has been subjected to radical changes, due to the impressive development of RES generation, in particular solar PV and wind. In fact, solar PV generation passed from 1.9 TWh in 2010 up to 23.9 TWh in 2015, whereas wind increased from 9.1 TWh in 2010 to 14.7 TWh in 2015. Hydro generation also has a relevant share of electricity generation, but the installed capacity is approximately constant, because all the potential for building large hydro power plants has been already completely exploited. Some possibilities exist only for the development of small and mini hydro power plants.

Fossil fueled power plants still represent a large share of the electricity generation mix, but their generation constantly decreases due to the fact that they are displaced from the plants "merit order" [4]. This situation is worsened by the contemporary reduction of the electricity consumption, determined prevalently by the economic downturn and partially by the implementation of energy efficiency measures.

The situation is particularly critical for combined cycle gas turbine (CCGT) plants, which substantially reduced their load factor, even though many of them are new and with a high efficiency.

All this has determined a significant reduction of the carbon intensity of the electricity generation sector; in fact, in 2015 , $40 \%$ of the generation was due to RES (17\% hydro and $23 \%$ other RES).

This context makes attractive the switching of the heat generation from the gas market to the electricity market, namely the switch from boilers to electrical heat pumps.

\section{ENERGY SYSTEM MODEL}

In order to assess the convenience of the fuel switching from natural gas to electricity of the Italian heating demand and the consequent utilization of electrical heat pumps instead of natural gas boilers, a model of the Italian energy system has been built by using the software EnergyPLAN [9].

EnergyPLAN is a free to download, user-friendly tool for energy systems analysis. The tool has been developed and expanded on a continuous basis since 1999 by the Sustainable Energy Planning Research Group at Aalborg University.
It is a deterministic computational model thought for the analysis of energy systems, which optimizes the management of a given system according to inputs and strategies chosen by the user from a proposed list.

The main purpose of the tool is to assist the design and assessment of national energy planning strategies by considering technical, economic and environmental data and constraints. In this way it is possible to optimize investments allocation and strategic planning of energy systems.

The main inputs are demand, renewable energy generation profile, energy plant capacities, fuel costs, and capex. Moreover, it is necessary to choose a strategy for import/export management.

The following hourly inputs have been provided to the model: electricity demand, PV generation profile, wind generation profile, run of river hydro generation profile and geo-thermal generation profile.

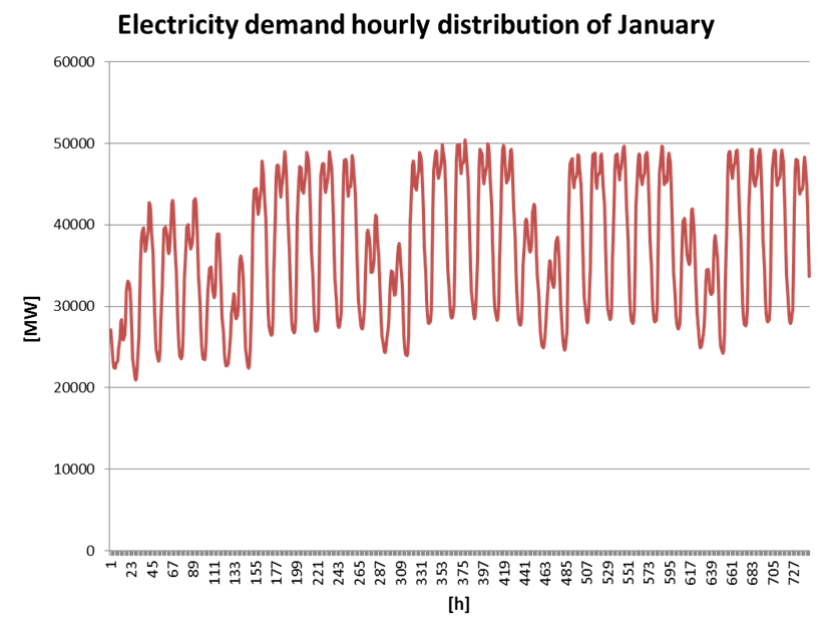

Figure 1. Example of hourly electricity demand distribution

Furthermore, the fossil fuels generation facilities are modeled, but EnergyPLAN offers limited capabilities to describe them. In particular, all the power plants must be introduced in an aggregate form (the shares of the different fossil fuels in input can be defined) and with a total average efficiency.

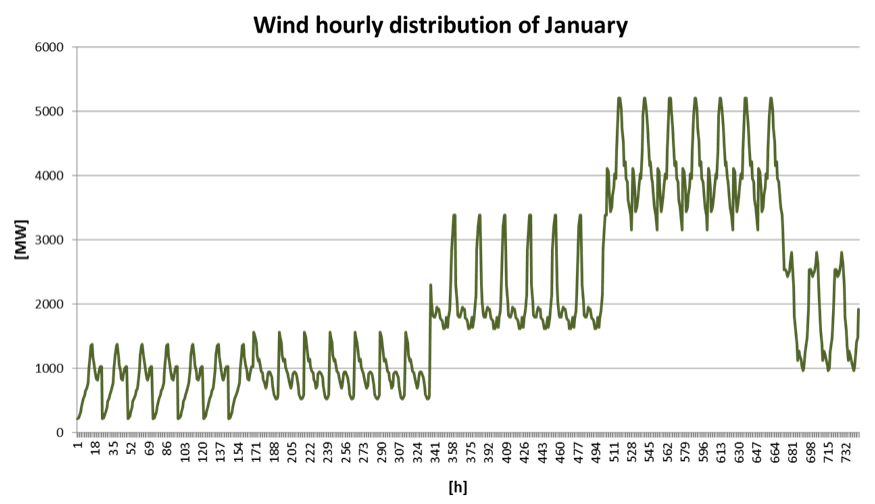

Figure 2. Example of wind generation hourly distribution

After modeling the electricity generation sector, the residential heating sector has been considered. In particular, the focus is on the individual systems, which can be mainly 
represented by boilers and heat pumps. The heat demand is given as an input and it was taken from [10].

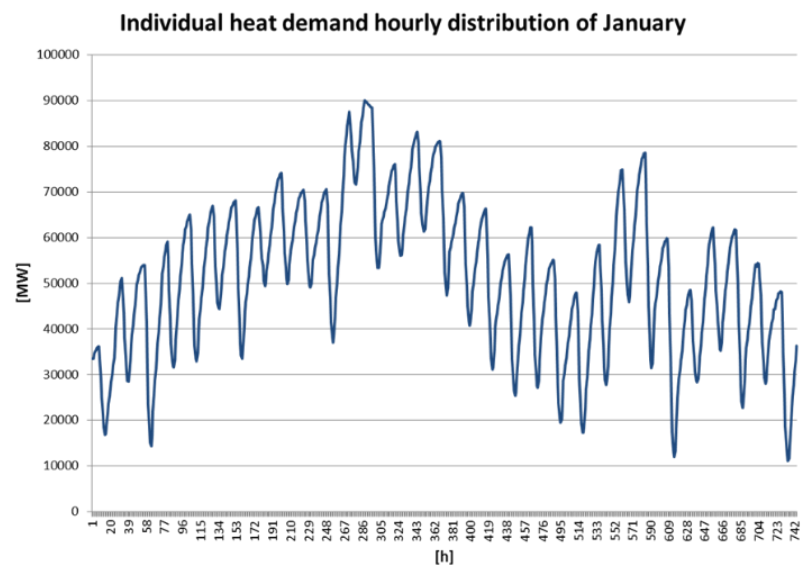

Figure 3. Example of heat demand hourly distribution.

In the reference system it is assumed that heat pumps have a negligible share and the heat demand is satisfied by means of boilers fueled with natural gas and fuel oil.

Furthermore, in order to determine the carbon emission, it is necessary to specify the emission factor of all the considered fuels, in the present study the following values were considered:

$-\mathrm{CO}_{2}$ content in coal: $98,5 \mathrm{~kg} / \mathrm{GJ}$

$-\mathrm{CO}_{2}$ content in natural gas: $72,9 \mathrm{~kg} / \mathrm{GJ}$

$-\mathrm{CO}_{2}$ content in fuel oil, diesel, petrol: $56,7 \mathrm{~kg} / \mathrm{GJ}$

- $\mathrm{CO}_{2}$ content in LNG: $59,64 \mathrm{~kg} / \mathrm{GJ}$

$-\mathrm{CO}_{2}$ content in the waste: $32,5 \mathrm{~kg} / \mathrm{GJ}$

\section{ANALYSIS OF THE RESULTS}

In order to assess the impact that the utilization of heat pumps for buildings heating has on the Italian energy systems, different simulations have been implemented by taking into account two parameters, namely penetration of heat pumps and their COP. Penetration is hypothesized to vary between $10 \%$ and $50 \%$, which means that an amount of the heating demand within $10 \%-50 \%$ is covered by heat pumps. At the same time, COP is assumed to vary between 2 and 4 .

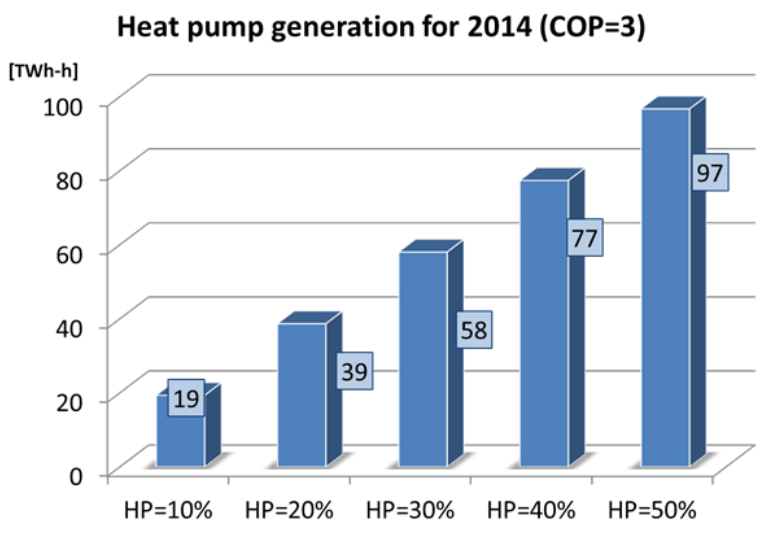

Figure 4. Heat demand covered by the heat pumps according to the level of penetration
Figure 4 reports the amount of heat demand covered by the heat pumps according to their level of penetration. If this amount of heat demand is covered by heat pumps, there will be a decrease of heat generated by fuel oil and natural gas boilers as per effect on the substitution. Anyhow this does not mean that less primary fuel is consumed at system level, because electricity consumption will increase and electricity is generated also by using fossil fuels.

The increase of electricity consumption is reported in Figure 5. Clearly, at the increase of heat pumps penetration will correspond a rise of electricity consumption.

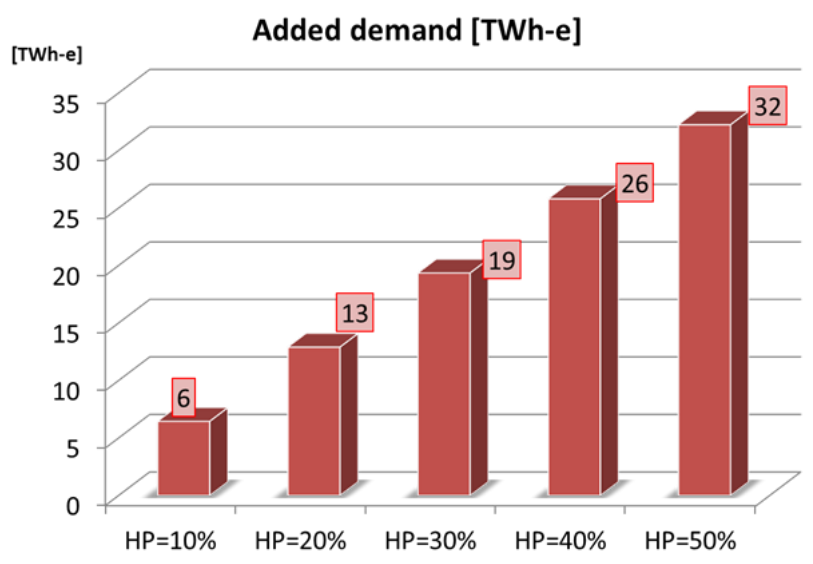

Figure 5. Increase of electricity consumption due to heat pumps utilization for buildings heating

The switching from fuel oil and natural gas boilers to electric heat pumps for heating purposes has an impact on the total primary energy consumption. In particular, a reduction of natural gas and fuel oil is detected, since part of them is substituted by heat pumps, which determine an increase of the electricity demand. This "added demand" will determine an extra generation of electricity with a corresponding consumption of primary energy which depends on the electricity generation mix available in the country.

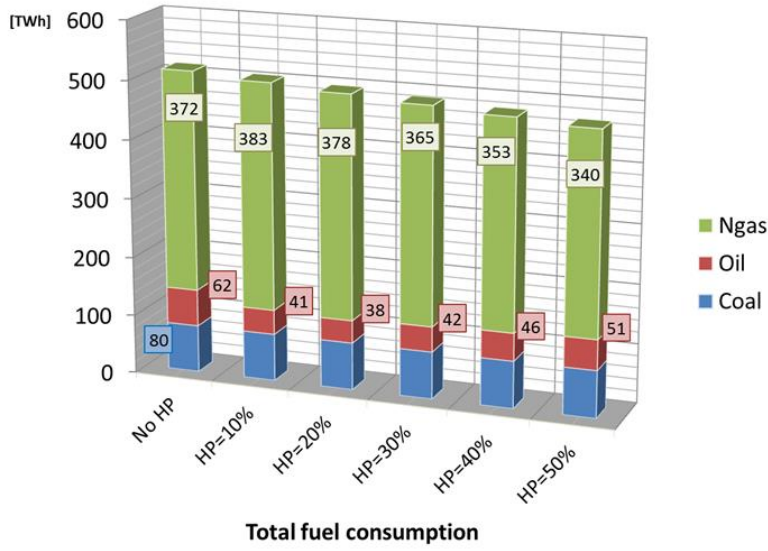

Figure 6. Primary energy consumption as a function of the penetration for $\mathrm{COP}=3$

Figure 6 shows how at the variation of heat pumps penetration corresponds a different consumption of primary energy. In particular, a relevant decrease of natural gas is detected. As for fuel oil, it decreases up to a penetration of $20 \%$. This is due to the fact that there is a substitution of fuel 
oil boilers with heat pumps, but at the same the increase of electricity consumption causes an increase of oil consumption for electricity generation. Up to a penetration of $20 \%$ the effect of substitutions prevails on the electricity generation effect and a net reduction of fuel oil consumption is obtained. When the penetration increases to values higher of $20 \%$, the electricity generation effect overcomes and there is a net increase of fuel oil consumption.

Anyway, the overall effect is positive from the point of view of the reduction of primary energy consumption and environmental effects. It is important to mention that the reduction of primary energy consumption can be considered positive also from the point of view of energy dependency and security of energy supply. Italy is poor in primary energy resources, therefore it has to import both natural gas and fuel oil. A lower consumption of these sources means a higher energy independence from the import of third countries, which increases the level of energy supply security, since the country is less exposed to extra territorial disputes.

Figure 7 highlights the carbon emissions according to the different penetration levels and it can be observed a continuous reduction as the heat pumps penetration increases.

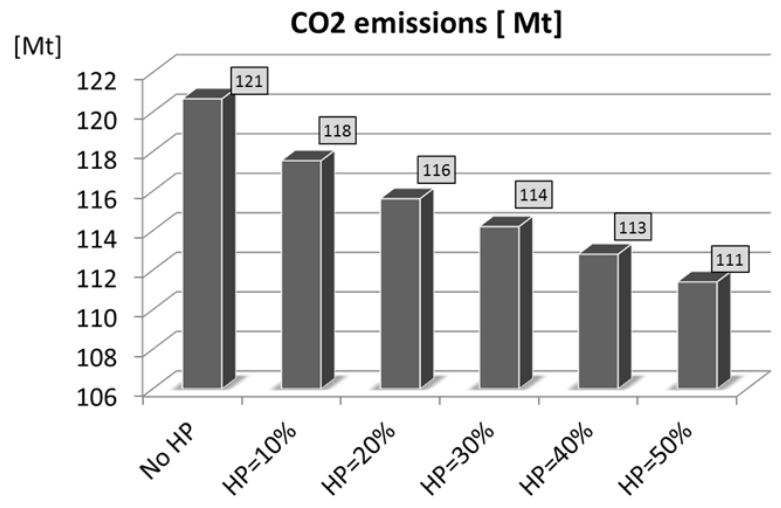

Figure 7. Carbon emissions according to the heat pumps penetration level

The reduction of carbon emissions has a positive impact on the environment, since a lower quantity of greenhouse gas is released in the atmosphere. Similarly, also pollutant emissions, such as $\mathrm{NO}_{\mathrm{x}}, \mathrm{SO}_{\mathrm{x}}$ and soot, are reduced as consequence of heat pumps utilization.

The decrease of the environmental impact has also a positive effect from the economic point of view, because it determines a reduction of the externalities cost.

Similarly, the decrease of primary energy consumption also has a positive economic effect, because a lower amount of fuel oil and natural gas needs to be imported from third countries. This determines a relevant saving which can be invested in other initiatives, which can generate value for the Italian economy.

Figure 8 reports the variation of the load factor in the winter months as a function of the heat pumps penetration. This parameter is of fundamental importance, since it helps to understand if the heat pumps load can be sustained by the Italian power system. By analyzing the values reported in Fig. 8 , it can be reasonably assumed that the system can support the development of heat pumps for buildings heating.

The maximum detected load factor if $40 \%$ in the month of February by assuming a penetration of the heat pumps equal to $40 \%$. This value of load factor can be safely achieved by a natural gas plants, CCGT in the case of the Italian power system, which were designed at nearly baseload conditions (e.g. $\sim 70 \%$ ), but as consequence of the unexpected quick development of renewables, CCGTs are now working only in peak hours with load factors of $\sim 30 \%$ [4].

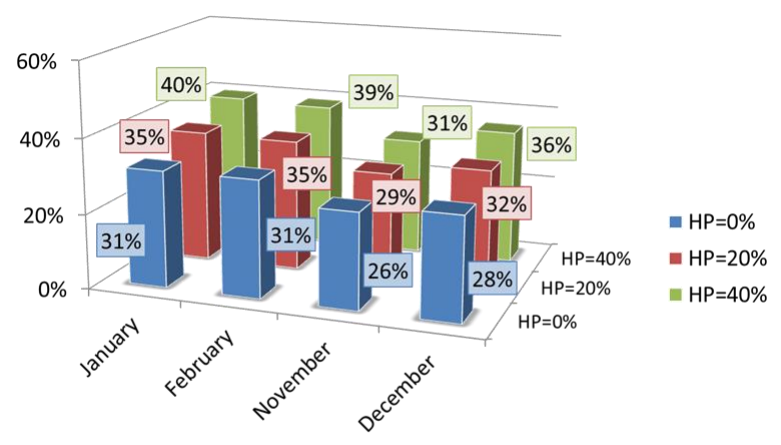

Load Factor for Electricity Production by Ngas Plants

Figure 8. Load factor of natural gas power plants according to the heat pumps penetration

The utilization of heat pumps for buildings heating could be an important option for the better utilization of relatively new CCGTs that, due to market conditions are underused with respect to their potential, also in light of their relatively high value of energy conversion (i.e. 54\% in average) [4].

This could also guarantee adequate margins for these plants on the energy market, because they currently suffer a "missing money" problem, in fact, different discussions are in place at European level regarding the capacity payment or the capacity market, in order to give thermal power plants another source of revenues. The absence of an adequate investment rewarding would cause the phase out of many power plants by creating a severe problem in terms of security and reliability of the power system.

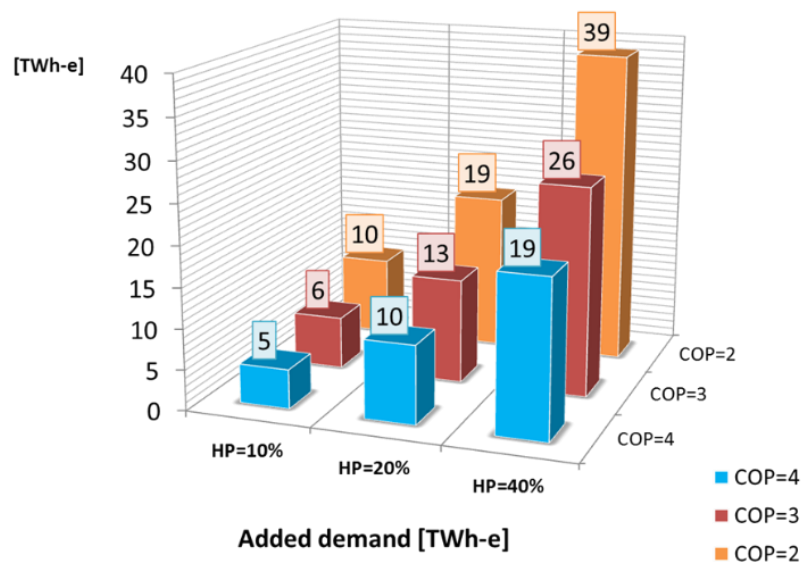

Figure 9. Electricity consumption of heat pumps as function of the COP

All the reported analysis was developed by assuming an average COP equal to 3 , therefore in order to understand at what extent the results are affected by this value, a sensitivity analysis was performed with COP equal to 2 and 4 . 
Figure 9 reports the variation of energy consumption according to the COP value. The electricity consumption varies linearly with the COP, but the primary energy saving and emissions are not linked to the COP by a linear relationship.

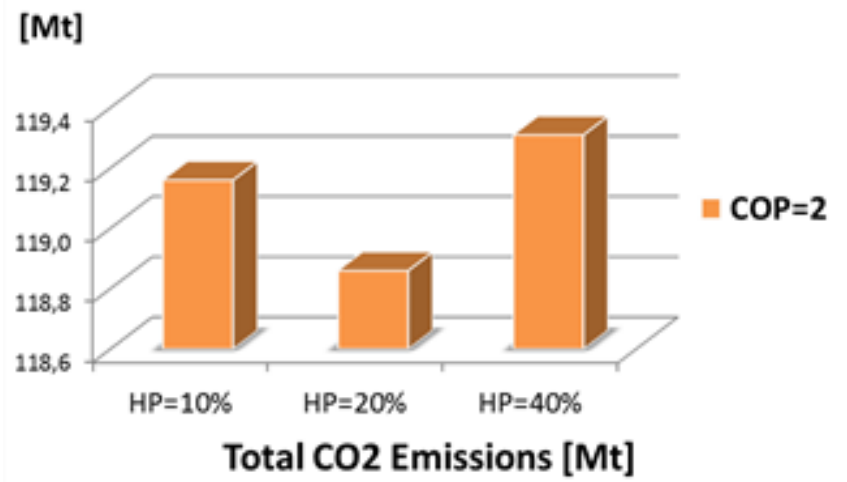

Figure 10. Carbon emission for $\mathrm{COP}=2$ and different levels of penetration

The analysis of Figure 10 reveals that for a penetration of the heat pumps equal to $40 \%$ there is an increase of carbon emission. This means that primary energy consumption is increased, therefore, according to Fig. 9, it is not convenient to satisfy more than $20 \%$ of the heat demand with heat pumps. A penetration of $20 \%$ results optimal for the system.

This is due to the fact that the lower COP determines a higher electricity consumption of the heat pumps, which requires a higher level of electricity generation. Once that the "energy excess" generated by renewables is absorbed, the further electricity demand must be covered with thermal power plants. If the amount of electricity to be generated by thermal power plants is relevant, also the less efficient plants will be called to produce, this determines an unfavorable "electricity to heat" ratio, which causes an increase of primary energy consumption.

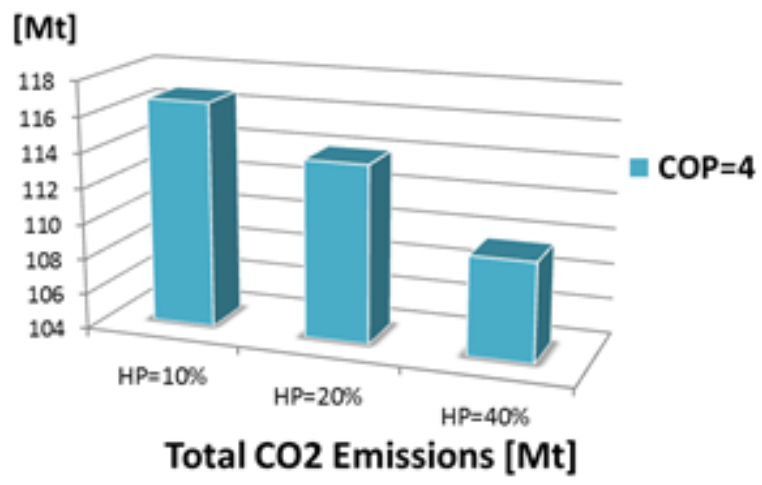

Figure 11. Carbon emission for $\mathrm{COP}=4$ and different levels of penetration

If the COP is assumed to be equal to 4 , the higher is the penetration of heat pumps and the higher is the reduction of carbon emissions, as shown in Figure 11. This is due to the fact that a $\mathrm{COP}=4$ determines a convenient "electricity to heat" ratio, therefore the system becomes more efficient.

In light of the presented results, it is noticed that only efficient heat pumps have to be considered in order to make the system more efficient and to reduce the consumption of primary energy.

\section{CONCLUSIONS}

The present work analyzed the possibility to use electrical heat pumps for buildings heating in order to reduce primary energy consumption in the Italian energy system.

The study was developed by using an energy system simulation software, namely EnergyPLAN, which allowed to represent the Italian energy system, with a specific focus on electricity generation and buildings heating. According to the proposed model, the following consideration can be drawn:

(1) Electrical heat pumps could be usually employed for buildings heating in the Italian energy system in order to decrease the primary energy consumption, provided that they have an appropriate COP.

(2) More detailed analysis are necessary to assess the environmental impact of the heat pumps. From the point of view of primary energy savings they have a positive impact, but, on the other hand, the environmental impact of the refrigerant must be taken into account as well.

(3) To support the utilization of heat pumps for buildings heating it is necessary to promote adequate policies which stimulate their usage. For example, convenient electricity tariffs/promotion should be promoted to support the switch from the natural gas/fuel oil systems to electrical heat pumps.

The proposed study can be further developed by including a detailed environmental and economic analysis, in order to evaluate in detail its overall feasibility.

\section{ACKNOWLEDGMENT}

Authors want to acknowledge the support of University of Genoa (PRA 2015 Fund 100025-2015-VB-DIP_001) and the Italian Ministry of Education, University and Research (PRIN project n. 2015M8S2PA).

\section{REFERENCES}

[1] Bertrand A., Aggoune R., Maréchal F. (2017). Inbuilding waste water heat recovery: An urban-scale method for the characterization of water streams and the assessment of energy savings and costs, Applied Energy, Vol. 192, pp. 110-125. DOI: 10.1016/j.apenergy.2017.01.096

[2] Bianco V., Scarpa F., Tagliafico L.A. (2015). Current situation and future perspectives of European natural gas sector, Frontiers in Energy, Vol. 9, No. 1, pp. 1-6. DOI: $10.1007 / \mathrm{s} 11708-014-0340-8$

[3] Richter M.F., Holz F. (2015). All quiet on the eastern front? Disruption scenarios of Russian natural gas supply to Europe, Energy Policy, Vol. 80, pp. 177-189. DOI: $10.1016 /$ j.enpol.2015.01.024

[4] Bianco V., Scarpa F., Tagliafico L.A. (2015). Long term outlook of primary energy consumption of the Italian thermoelectric sector: Impact of fuel and carbon prices, Energy, Vol. 87, pp. 153-164. DOI: 10.1016/j.energy.2015.04.097

[5] Del Rio P. (2011). Analyzing future trends of renewable electricity in the EU in a low-carbon context, Renewable and Sustainable Energy Reviews, Vol. 15, No. 5, pp. 2520-2533. DOI: 10.1016/j.rser.2010.12.013

[6] Menegaki A.N. (2013). Growth and renewable energy in Europe: Benchmarking with data envelopment 
analysis, Renewable Energy, Vol. 60. pp. 363-369. DOI: 10.1016/j.renene.2013.05.042

[7] Capros P., Mantzos L., Parousos L., Tasios N., Klaasse G., Van I.T. (2011). Analysis of the EU policy package on climate change and renewables, Energy Policy, Vol. 39, No. 3, pp. 1476-1485. DOI: 10.1016/j.enpol.2010.12.020

[8] Bianco V., Scarpa F., Tagliafico L.A. (2017). Estimation of primary energy savings by using heat pumps for heating purposes in the residential sector, Applied Thermal Engineering, Vol. 114, pp. 938-947. DOI: 10.1016/j.applthermaleng.2016.12.058

[9] Østergaard P.A. (2015). Reviewing Energy plan simulations and performance indicator applications in Energy plan simulations, Applied Energy, Vol. 154, pp. 921-933. DOI: 10.1016/j.apenergy.2015.05.086

[10] Stratego Project. from http://stratego-project.eu/reports accessed on 24 August 2017 